\title{
Measurement of Monocyclic Aromatic Amines in an Urban Air
}

\author{
Inkyu Han ${ }^{1,2}$, Je-Seung Lee ${ }^{3} \&$ Soo-Mi Eo ${ }^{3}$ \\ ${ }^{1}$ Division of Epidemiology, Human Genetics, and Environmental Sciences, University of Texas Health Science \\ Center at Houston School of Public Health, Houston, TX, USA \\ ${ }^{2}$ Southwest Center for Occupational and Environmental Health, University of Texas Health Science Center at \\ Houston, Houston, TX, USA \\ ${ }^{3}$ Seoul Metropolitan Government Research Institute of Public Health and Environment, Seoul, Korea \\ Correspondence: Inkyu Han, Division of Epidemiology, Human Genetics, and Environmental Sciences, \\ University of Texas Health Science Center at Houston School of Public Health, 1200 Pressler Street, Houston, \\ TX 77030, USA. Tel: 1-713-500-9260. E-mail: Inkyu.Han@uth.tmc.edu
}

\author{
Received: April 14, 2014 Accepted: May 14, 2014 Online Published: May 16, 2014 \\ doi:10.5539/ep.v3n3p14 URL: http://dx.doi.org/10.5539/ep.v3n3p14
}

\begin{abstract}
Personal air exposure to monocyclic aromatic amines (MAA) is a growing concern, in large part, due to their ubiquitous presence in the general environment and their potential health risk for bladder cancer. It is unclear what other sources of airborne MAA are for general population, due to low concentrations in the air. Detecting "trace" levels of MAAs requires a sensitive analytical method and field evaluation. In this study, an analytical method was developed to detect 2,3-dimethylaniline [2,3-DMA]; 3,5-DMA; and 3-ethylaniline [3-EA] in general air environment. During a 12-hr sampling periods, the estimated limit of quantifications (LOQs) were less than $4.13 \mathrm{ng} / \mathrm{m}^{3}$ for 2,3-DMA; 3,5-DMA; and 3-EA. Desorption efficiencies (recovery rates) were at least $89 \%$ with 1 ng of each 2,3-DMA; 3,5-DMA; and 3-EA per tube. The storage effect for three MAAs showed that all three MAAs remained above $60 \%$ on the sorbent tubes and filters over 10 days. A field study was conducted in Seoul, Korea to validate sampling method in a real-world busy street with traffic, an office near the same street, and a residential home away from the busy street. Gas-phase 2,3-DMA was detected only in the indoor home sample $\left(3.26 \pm 0.60 \mathrm{ng} / \mathrm{m}^{3}\right)$, and 3,5-DMA was not detected in all samples. Particle-bound 3-EA was detected in the street $\left(10.92 \pm 4.73 \mathrm{ng} / \mathrm{m}^{3}\right)$, office $\left(9.47 \pm 6.11 \mathrm{ng} / \mathrm{m}^{3}\right)$, and residential home $\left(7.53 \pm 4.17 \mathrm{ng} / \mathrm{m}^{3}\right)$. The results suggested that the proposed analytical and field sampling methods can useful for environmental exposure assessment of these MAAs.
\end{abstract}

Keywords: monocyclic aromatic amine, analytical method, field evaluation, urban air, exposure assessment

\section{Introduction}

The health effects of 2,3-dimethylaniline (2,3-DMA); 3,5-dimethylaniline (3,5-DMA); and 3-ethylaniline (3-EA), a class of aromatic amines (AAs), are a growing concern due to their similar chemical structures to carcinogens such as aniline and 2,6-dimethylaniline (Gan et al., 2004; Skipper et al., 2006). Exposure to these compounds can be ubiquitous because these AAs are widely used in work places as well as general environments as dyes, pharmaceuticals, cosmetics, agricultural pesticides, antioxidants in polymers, and motor fuels (Kutting et al., 2009; Skipper, Kim, Sun, Wogan, \& Tannenbaum, 2010; Angerer, Ewers, \& Wilhelm 2007; Scherer, 2005).

Personal exposure assessment to airborne AAs has been conducted in work places in the past 20 years (Ward et al., 1996; Talaska \& Al-Zoughool, 2003). Occupational exposure studies found that aniline and benzidine, a class of AAs, were associated with increase risk for bladder cancer in dyers, painters, and hairdressers (Naito et al., 1995; Sathiakumar \& Delzell, 2000; Talaska, 2003). In the general environment, previous exposure studies found that smoking contributed to increase in indoor concentrations of some AAs such as aniline and 4-aminobiphenyl (Van Hemelrijck, Michaud, Connolly, \& Kabir, 2009; Hammond et al., 1993). Recent exposure studies, however, suggested that a set of specific AAs including 2,3-DMA; 3,5-DMA; and 3-EA may not be attributed to tobacco smoke (Gan et al., 2004; Skipper et al., 2010). Unlike aniline and 4-aminobiphenyl, the environmental sources of personal air exposure to these compounds are still unknown and very little is understood about the airborne concentrations that potentially put an individual at risk for bladder cancer, because of lack of robust methods for quantifying AAs in air. 
Few studies have tried to measure airborne 2,3-DMA; 3,5-DMA; and 3-EA in general environments worldwide (Palmiotto, Pieraccini, Moneti, \& Dolara, 2001; Zhu \& Aikawa, 2004; Ning et al., 2005). Furthermore, few studies have successfully detected airborne concentrations of these chemicals due to the absence of a sensitive method that can detect trace levels in the air. In addition, while these compounds can exist in the air as gas-phase and particle-phase, only one study has examined both gas-phase and particle-phase of these compounds (Akyuz, 2008). It is clear that a significantly more sensitive, rapid, and simple method is needed to allow for robust measurements of these compounds for the general population.

In this study we developed an analytical method to detect low levels of airborne gas and particle phase of 2,3-DMA; 3,5-DMA; and 3-EA. We also evaluated the feasibility of detecting ambient AAs in a real-world urban environment.

\section{Methods}

\subsection{Sampling Locations}

Sampling locations in Seoul Korea were a street vendor booth on a street with busy traffic (Gangnam St.), an office located on the same street (first floor), and a residential home located $5 \mathrm{~km}$ east from the Gangnam site. Gangnam Street is an 8-lane road which supports all types of vehicles including passenger cars, taxis, as well as diesel-powered buses and trucks. Sampling was conducted from September 23 to October 1, 2010. Street vendor booth samples were collected for 7 days, office samples were collected for 3 days, and residential home samples were collected for 6 days. Street vendor booths are ubiquitous in this area, and the booths are typically located about $1 \mathrm{~m}$ from the car lane. The samplers were deployed on the outside wall of the booth in sequential 4-hr intervals from 07:00 to 19:00 (12 hrs). The concentrations of AAs for the street vendor booth were reported as a 12-hr integrated sample by combining the three samples for each day. For the office measurement, a sampler was deployed on a desk between 08:00-18:00 (10 hrs) for 3 days. For indoor home sampling, a sampler was deployed in a living room at 06:00 and removed 20:00 (14 hrs) for 6 days. The inlet of all samplers in each location was placed approximately $1.5 \mathrm{~m}$ above ground level.

\subsection{Sampling Equipment}

To collect particle bound AAs, we used $37 \mathrm{~mm}$ glass fiber filters treated with $0.26 \mathrm{~N}$ sulfuric acid in polystyrene cassettes assembled by the manufacturer (SKC Inc., Eighty Four, PA). Gas phase AAs were collected using XAD-7 sorbent tubes coated with 10\% phosphoric acid (SKC Inc., Eighty Four, PA). The cassette and sorbent tube were attached in series to a low flow sampling pump (SKC Inc, Pocket Pump 210 series, Eighty Four, PA). The sampling flow rate was calibrated at $200 \mathrm{~mL} / \mathrm{min}$ prior to field sampling and then measured after field sampling. At the end of each sampling period samplers were capped and stored at ambient temperature until transport to the Seoul Metropolitan Government Research Institute of Public Health and Environment (SMG-RIPHE). A field blank was used at each location for each sampling day.

\subsection{Reagents}

A standard stock solution was prepared by adding $1 \mathrm{~mL}$ of 2,3-DMA (99\%); 3,5-DMA (98\%); and 3-EA (98\%), separately, into a $10 \mathrm{~mL}$ volumetric flask. Reagent grade methanol (ACS reagent grade $(\mathrm{GC})>99.8 \%$, Sigma-Aldrich, St. Louis, MO) was added into the volumetric flask to make $10 \mathrm{~mL}$ of stock solution with 100 $\mathrm{mg} / \mathrm{mL}$ for each compound. 2,3-DMA; 3,5-DMA; and 3-EA were purchased from Sigma-Aldrich (St. Louis, MO). The concentrations of standard solution ranged from $0.025 \mathrm{ng} / \mu \mathrm{L}$ to $4.9 \mathrm{ng} / \mu \mathrm{L}$. Internal standard (aniline-2,3,4,5- $\mathrm{d}_{5}$ solution, Supelco, Park Bellefonte, PA) was separately prepared and added into all standard solutions to a concentration of $0.5 \mathrm{ng} / \mu \mathrm{L}$. Desorbing solution was prepared by adding ammonium hydroxide (5.0 $\mathrm{N}$ in water, Sigma-Aldrich, St. Louis, $\mathrm{MO}$ ) to methanol at $0.2 \mathrm{~N}$ concentrations. Internal standard was added into the desorbing solution.

\subsection{Sample Extraction}

To assess ambient concentrations of AAs, we used a modification of the National Institute of Occupational Safety and Health (NIOSH) 2017 method for particle bound AAs and Occupational Safety and Health Administration (OSHA) PV2079 method for gas phase AAs. Glass fiber filters taken from the polystyrene cassette were transferred to $4 \mathrm{~mL}$ amber vials. Sorbent tubes were opened and the front and back section of each tube were placed in separate $4 \mathrm{~mL}$ vials. Each amber vial was desorbed with $2 \mathrm{~mL}$ of the desorbing solution. The vial was sealed immediately and sonicated in a water bath (Branson, Model 2510, Danbury, CT) for 1 hour to extract AAs. After cooling the vials to room temperature, the aliquots were filtered through $0.25 \mu \mathrm{m}$ polypropylene syringe filters (Whatman, Puradisc 13, Clifton, NJ) into $2 \mathrm{~mL}$ amber vials. The filtered aliquots were analyzed by Gas Chromatography (GC). 


\subsection{Analytical Conditions}

An Agilent 7890A GC coupled with 5975C XL MSD (Agilent Technologies, Palo Alto, CA) was used for AAs analyses. AAs were separated on a $30 \mathrm{~m} \times 0.25 \mathrm{~mm}$ i.d. $\times 250 \mathrm{~nm}$ film thickness Agilent DB-5 MS Column (Palo Alto, CA) with the following oven temperature program: initial temperature was set at $50{ }^{\circ} \mathrm{C}$ for 2 min, increased to $110{ }^{\circ} \mathrm{C}$ at $3{ }^{\circ} \mathrm{C} / \mathrm{min}$ and finally increased to $280{ }^{\circ} \mathrm{C}$ at $30^{\circ} \mathrm{C} / \mathrm{min}$ holding at $280{ }^{\circ} \mathrm{C}$ for $6 \mathrm{~min}$. Temperatures of the sample inlet and MS source were $280{ }^{\circ} \mathrm{C}$ and $290^{\circ} \mathrm{C}$, respectively. Flow rate on the column was $1.1 \mathrm{~mL} / \mathrm{min}$. Selected Ion Monitoring (SIM) mode was used for MS operations.

\section{Results}

\subsection{Validation of Analytical Method}

Instrument detection limit (IDL) was determined with a standard solution of $0.025 \mathrm{ng} / \mu \mathrm{L}$ for each alkylaniline in 7 replicate analyses (Table 1). The IDL was determined by multiplying three times the standard deviation (SD) of the 7 replicates. IDL ranged from 0.02 to $0.18 \mathrm{ng} / \mu \mathrm{L}$ for all three AAs. The limit of quantification (LOQ) was estimated by $(3.3 \times \mathrm{IDL}) / 0.144 \mathrm{~m}^{3}$ of air assuming a $12-\mathrm{hr}$ sample at $200 \mathrm{~mL} / \mathrm{min}$. The estimated LOQs ranged between $0.46-2.06 \mathrm{ng} / \mathrm{m}^{3}$ for $3-\mathrm{EA} ; 3.21-4.13 \mathrm{ng} / \mathrm{m}^{3}$ for $3,5-\mathrm{DMA}$; and $1.83-2.25 \mathrm{ng} / \mathrm{m}^{3}$ for 2,3-DMA. Desorption efficiency was tested for the three AAs by spiking $1 \mathrm{ng}$ per tube and filter. The desorption efficiency ranged from 89 to $118 \%$. To determine precision, both sorbent tubes and glass fiber filters were separately spiked with a $1 \mu \mathrm{l}$ of standard solution containing $0.5 \mathrm{ng} / \mu \mathrm{L}$ of each AA. Precision was reported as percent relative standard deviation (\% RSD). Precision for each AA was less than $10 \%$ except for gas-phase 3,5-DMA $(12 \%)$.

Table 1. Summary of analytical condition, instrument detection limit (IDL), estimated limit of quantification (LOQ) and precision

\begin{tabular}{|c|c|c|c|c|c|c|c|c|}
\hline Compound & RT (min) & M.W & Q1 & Q2 & Media & IDL $(\mathrm{ng} / \mu \mathrm{l})$ & LOQ $\left(\mathrm{ng} / \mathrm{m}^{3}\right)$ & Precision (\% RSD) \\
\hline \multirow{2}{*}{ 3-EA } & \multirow{2}{*}{18.248} & \multirow{2}{*}{106} & \multirow{2}{*}{121} & \multirow{2}{*}{77} & XAD-7 & 0.02 & 0.46 & 6.6 \\
\hline & & & & & Filter & 0.09 & 2.06 & 8.8 \\
\hline \multirow{2}{*}{ 3,5-DMA } & \multirow{2}{*}{18.474} & \multirow{2}{*}{121} & \multirow{2}{*}{106} & \multirow[b]{2}{*}{77} & XAD-7 & 0.18 & 4.13 & 12.2 \\
\hline & & & & & Filter & 0.14 & 3.21 & 4.7 \\
\hline \multirow{2}{*}{ 2,3-DMA } & \multirow{2}{*}{19.446} & \multirow{2}{*}{121} & \multirow{2}{*}{106} & \multirow{2}{*}{77} & XAD-7 & 0.11 & 2.52 & 7.1 \\
\hline & & & & & Filter & 0.08 & 1.83 & 3.1 \\
\hline
\end{tabular}

\subsection{Storage Effect}

The stability of all three AAs on XAD-7 sorbent tubes and filters was tested at the UTSPH laboratory, to examine when field samples should be analyzed after sample collection. Sorbent tubes and filters were spiked with a $1 \mu \mathrm{l}$ of standard solution containing $1 \mathrm{ng} / \mu \mathrm{L}$ of each AA, and stored in amber jars for $1,3,5$, and 10 days at room temperature prior to being analyzed. The percent amount remaining of AA per storage days is shown in Figure 1. The spiked AAs were retained at $75-97 \%$ on sorbent tubes from day 1 to day 10 (Figure 1a). NIOSH method PV 2079 reported that XAD-7 sorbent tubes spiked with $570 \mu \mathrm{g}(5 \mathrm{ppm})$ of aniline retained 81-87\% after 7 days of ambient temperature storage. The three AAs spiked on glass fiber filters decreased to $72-78 \%$ at day $1,62-68 \%$ at day 5 and $59-72 \%$ by day 10 (Figure 1 b). Given our results, all field samples were analyzed within 5 days of sampling.

\subsection{Measurement of Alkylanilines in Urban Air}

A total of 32 samples (16 particle phase and 16 gaseous phase) were analyzed for 2,3-DMA; 3,5-DMA; and 3-EA at three locations. Gas phase 2,3-DMA was only detected and quantified in 5 out of the 6 sampling days in a residential home (Table 2). The average concentration of 2,3-DMA in the home was $3.78 \pm 0.83 \mathrm{ng} / \mathrm{m}^{3}$. Gas phase 2,3-DMA was not detected in either Gangnam Street and the office. Only particle bound 3-EA was detected and quantified by GC/MS at all locations (Table 3). Average concentrations of particle bound 3-EA were $10.92 \pm 4.73 \mathrm{ng} / \mathrm{m}^{3}$ at Gangnam Street followed by the office $\left(9.47 \pm 6.11 \mathrm{ng} / \mathrm{m}^{3}\right)$ and home $(7.53 \pm 4.17$ $\mathrm{ng} / \mathrm{m}^{3}$ ). 3,5-DMA was not detected in either of the particle bound or gas phase samples for all locations. 

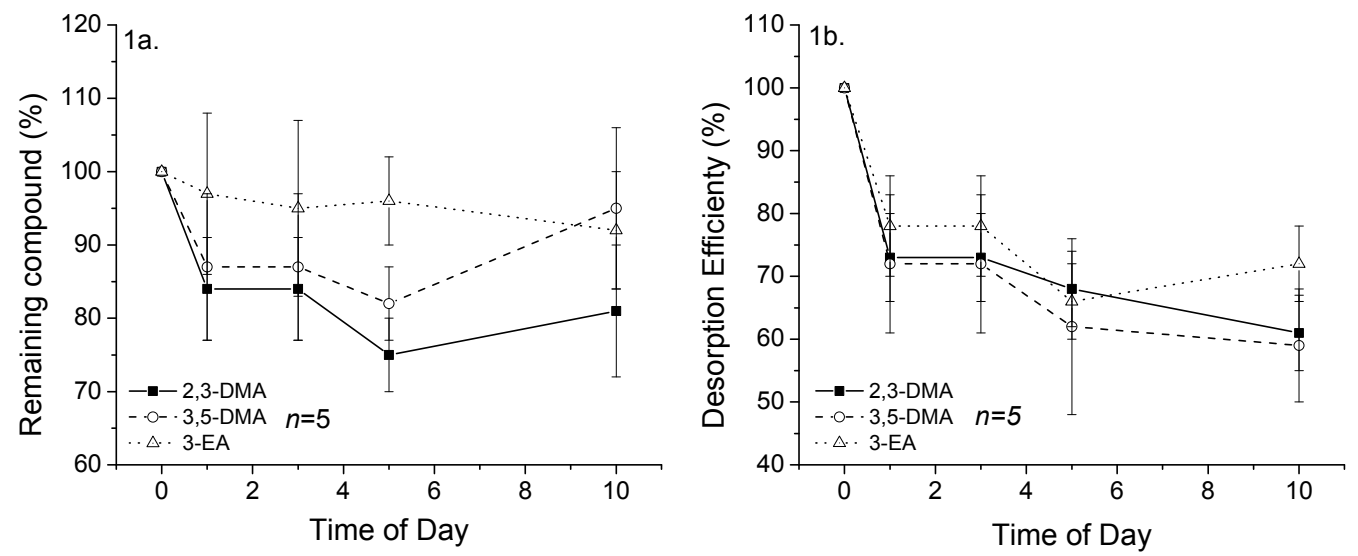

Figure 1. Storage effect of 2,3-dimethylaniline; 3,5-dimethylaniline and 3-ethylaniline. Percentages of three MAAs remaining in the XAD-7 tubes (Figure 1a) and glass fiber filters (Figure 1b) after different storage time at room temperature

Table 2. Descriptive results of gas phase 2,3-dimethylaniline

\begin{tabular}{llllllllll}
\hline Gaseous & $9 / 23$ & $9 / 24$ & $9 / 25$ & $9 / 26$ & $9 / 27$ & $9 / 28$ & $9 / 29$ & $9 / 30$ & $10 / 1$ \\
$2,3-D M A$ & (Thr) & (Fri) & (Sat) & (Sun) & (Mon) & (Tue) & (Wed) & (Thr) & (Fri) \\
\hline Street (n=7) & ND & ND & ND & (NS) & ND & ND & ND & ND & (NS) \\
Home (n=6) & (NS) & $\mathbf{4 . 4 6}$ & $\mathbf{4 . 6 5}$ & (NS) & ND & $\mathbf{2 . 9 5}$ & $\mathbf{2 . 8 7}$ & $\mathbf{3 . 9 5}$ & (NS) \\
Office (n=3) & (NS) & (NS) & (NS) & (NS) & (NS) & (NS) & ND & ND & ND \\
\hline
\end{tabular}

Note: Not detected (ND); no sampling (NS).

Table 3. Descriptive results of particle-bound 3-ethylaniline

\begin{tabular}{llllllllll}
\hline \multirow{2}{*}{ Particle 3-EA } & $9 / 23$ & $9 / 24$ & $9 / 25$ & $9 / 26$ & $9 / 27$ & $9 / 28$ & $9 / 29$ & $9 / 30$ & $10 / 1$ \\
& (Thr) & (Fri) & (Sat) & (Sun) & (Mon) & (Tue) & (Wed) & (Thr) & (Fri) \\
\hline Street (n=7) & ND & ND & ND & (NS) & ND & $\mathbf{5 . 4 6}$ & $\mathbf{1 3 . 8 6}$ & $\mathbf{1 3 . 4 4}$ & (NS) \\
Home (n=6) & (NS) & ND & ND & (NS) & ND & $\mathbf{4 . 4 4}$ & $\mathbf{1 2 . 2 7}$ & $\mathbf{5 . 8 7}$ & (NS) \\
Office (n=3) & (NS) & (NS) & (NS) & (NS) & (NS) & (NS) & $\mathbf{5 . 8 9}$ & $\mathbf{6 . 0 0}$ & $\mathbf{1 6 . 5 2}$
\end{tabular}

Note: Not detected (ND); no sampling (NS).

\section{Discussion}

The estimated LOQs in this study ranged from $0.46 \mathrm{ng} / \mathrm{m}^{3}$ to $4.13 \mathrm{ng} / \mathrm{m}^{3}$ for three MAAs. The results in this study demonstrate improved sensitivity to detect these aromatic amines using a GC/MS compared to previous studies. For example, Research by Zhu and Aikawa (2004) reported LOQ values for 2-EA and 4-EA of $10 \mathrm{ng} / \mathrm{m}^{3}$ and $20 \mathrm{ng} / \mathrm{m}^{3}$, respectively (Zhu \& Aikawa, 2004), Another study by Zhu, Newhook, Marro and Chan (2005) reported a method detection limit of $1.2 \mu \mathrm{g} / \mathrm{m}^{3}$ for 3,5,-DMA (Zhu, Newhook, Marro, \& Chan, 2005). The desorption efficiency in this study was similar to other studies. For instance, NIOSH PV2079 method reported average desorption efficiency of $92 \%$ for aniline and other environmental monitoring studies also reported desorption efficiency ranges between 92 and $114 \%$ for some of methyl- and ethyl anilines (Akyuz, 2008; Zhu \& Aikawa, 2004; Zhu et al., 2005). The storage effects of the filters and sorbent tubes were similar to previous studies. In a Canadian study, Zhu and Aikawa (2004) tested storage effects of desorption tubes spiked with $1 \mathrm{ng}$ of 2-EA and 4-EA (Zhu \& Aikawa, 2004) and reported a retention of $60-80 \%$ after 5 days of storage.

In our field feasibility study, the detection of gas phase 2,3-DMA only in the indoor home samples suggest that the source of 2,3-DMA is related to cooking or other domestic activities. A housewife reported that she used vegetable cooking oils to fry food for meals at least once a day between $9 / 24-9 / 30$. Other potential sources of 
2,3-DMA in indoor homes can be the use of paints, cleaning agents, pesticides, and smoking. However, none of these potential sources were observed during the sampling period in the home.

Sources of airborne AAs can be emissions from industrial activities (Ge, Wexler, \& Clegg, 2011), motor vehicle exhaust, cooking, and biomass burning (He et al., 2010; Mohr et al., 2009; Sun et al., 2011). It is also possible that ambient air AAs can be formed from photochemical reactions with volatile organic compounds (Sun et al., 2011). Particle phase 3-EA in the non-smoking office and the home without smokers is likely derived from infiltration of PM from ambient air. In this study the average ratios of indoor/ambient (Gangnam St.) of particle bound 3-EA in home and office were less than 1 . The results are consistent with a previous study reported the indoor/outdoor ratio of aniline (0.93) in Canada (Zhu \& Aikawa, 2004).

The analytical condition and field sampling method showed that the three AAs are present as both gas and particle phase in ambient air and indoor air. This study provides the substantial evidence that general populations are exposed to monocyclic aromatic amines not attributed to smoking. In future health studies, this exposure assessment method can be useful to identify environmental exposure sources of MAA and to quantify the relationship between exposure and bladder cancer risk.

\section{Conclusion}

We have developed a sensitive analytical method to measure airborne 3-EA; 2,3-DMA; and 3,5-DMA and evaluated the feasibility of measuring these AA compounds in a real-world urban environment. Given the results from 8 days of intensive gas and particle phase sampling at three different locations, we reach the following conclusions: (1) limit of quantifications (LOQs) ranged $0.46-4.13 \mathrm{ng} / \mathrm{m}^{3}$ while those in previous studies ranged $10-20 \mathrm{ng} / \mathrm{m}^{3}$. (2) Desorption efficiencies ranged from $89-118 \%$ after spiking with $1 \mathrm{ng}$ of each 3-EA; 2,3-DMA; and 3,5-DMA per tube. (3) Low concentrations of AAs spiked on sorbent tubes and filters stored at room temperature remained above $60 \%$ after 10 days. (4) Field investigation showed that particle bound 3-EA was detected in indoor and outdoor ambient air. (5) Gas phase 2,3-DMA was detected only in the indoor home air and its emission source was potentially cooking activities. In conclusion, the established analytical method and field sampling strategy can be used for exposure assessment to these aromatic amines in general environment.

\section{Acknowledgements}

The study is in part supported by CDC/NIOSH T42OH008421 and the Office of the Dean at the University of Texas School of Public Health. Although the research described in this manuscript has been funded wholly or in part by CDC/NIOSH T42OH008421 to the UTSPH, it has not been subjected to the Agency's required peer and policy review and therefore does not necessarily reflect the views of the Agency and no official endorsement should be inferred.

\section{References}

Akyuz, M. (2008). Simultaneous determination of aliphatic and aromatic amines in ambient air and airborne particulate matters by gas chromatography-mass spectrometry. Atmospheric Environment, 42, 3809-3819. http://dx.doi.org/10.1016/j.atmosenv.2007.12.057

Angerer, J., Ewers, U., \& Wilhelm, M. (2007). Human biomonitoring: state of the art. International Journal of Hygiene and Environmental Health, 210, 201-28. http://dx.doi.org/ 10.1016/j.ijheh.2007.01.024

Gan, J. P., Skipper, P. L., Gago-Dominguez, M., Arakawa, K., Ross, R. K., Yu, M. C., \& Tannenbaum, S. R. (2004). Alkylaniline-hemoglobin adducts and risk of non-smoking-related bladder cancer. Journal of the National Cancer Institute, 96, 1425-1431. http://dx.doi.org/ 10.1093/jnci/djh274

Ge, X. L., Wexler, A. S., \& Clegg, S. L. (2011). Atmospheric amines - Part I. A review. Atmospheric Environment, 45, 524-546. http://dx.doi.org/10.1016/j.atmosenv.2010.10.012

Hammond, S. K., Coghlin, J., Gann, P. H., Paul, K., Taghizadeh, K., Skipper, P. L., \& Tannenbaum, S. R. (1993). Relationship between Environmental Tobacco-Smoke Exposure and Carcinogen Hemoglobin Adduct Levels in Nonsmokers. Journal of the National Cancer Institute, 85, 474-478.

He, L. Y., Lin, U., Huang, X. F., Guo, S., Xue, L., Su, Q., ... Zhang, Y. H. (2010). Characterization of high-resolution aerosol mass spectra of primary organic aerosol emissions from Chinese cooking and biomass burning. Atmospheric Chemistry and Physics, 10, 11535-11543. http://dx.doi.org/10.5194/acp-10-11535-2010

Kutting, B., Goen, T., Schwegler, U., Fromme, H., Uter, W., Angerer, J., \& Drexler, H. (2009). Monoarylamines in the general population - A cross-sectional population-based study including 1004 Bavarian subjects. 
International Journal of Hygiene and Environmental Health, 212, 298-309. http://dx.doi.org/10.1016/j.ijheh.2008.07.004

Mohr, C., Huffman, J. A., Cubison, M. J., Aiken, A. C., Docherty, K. S., Kimmel, J. R., ... Jimenez, J. L. (2009). Characterization of Primary Organic Aerosol Emissions from Meat Cooking, Trash Burning, and Motor Vehicles with High-Resolution Aerosol Mass Spectrometry and Comparison with Ambient and Chamber Observations. Environmental Science \& Technology, 43, 2443-2449. http://dx.doi.org/10.1021/es8011518

Naito, S., Tanaka, K., Koga, H., Kotoh, S., Hirohata, T., \& Kumazawa, J. (1995). Cancer Occurrence among Dyestuff Workers Exposed to Aromatic-Amines - a Long-Term Follow-up-Study. Cancer, 76, 1445-1452. http://dx.doi.org/10.1002/1097-0142(19951015)76:8<1445::AID-CNCR2820760823>3.0.CO;2-R

Ning, Z. W., Zhao, S. T., Wang, J., Hu, B., Zhu, Z. G., Huang, Y. D., \& Wang, D. (2005). Determination of aliphatic amines and heterocyclic amines in indoor air by a modified GC and GC/MS methods. Indoor Air 2005: Proceedings of the 10th International Conference on Indoor Air Quality and Climate, 1-5, 2048-2052.

Palmiotto, G., Pieraccini, G., Moneti, G., \& Dolara, P. (2001). Determination of the levels of aromatic amines in indoor and outdoor air in Italy. Chemosphere, 43, 355-361. http://dx.doi.org/10.1016/S0045-6535(00)00109-0

Sathiakumar, N., \& Delzell, E. (2000). An updated mortality study of workers at a dye and resin manufacturing plant. Journal of Occupational and Environmental Medicine, 42, $762-771$. http://dx.doi.org/10.1097/00043764-200007000-00012

Scherer, G. (2005). Biomonitoring of inhaled complex mixtures--ambient air, diesel exhaust and cigarette smoke. Experimental and Toxicolgic Pathology, 57(Suppl 1), 75-110. http://dx.doi.org/10.1016/j.etp.2005.05.007

Skipper, P. L., Kim, M. Y., Sun, H. L. P., Wogan, G. N., \& Tannenbaum, S. R. (2010). Monocyclic aromatic amines as potential human carcinogens: old is new again. Carcinogenesis, 31, 50-58. http://dx.doi.org/10.1093/carcin/bgp267

Skipper, P. L., Trudel, L. J., Kensler, T. W., Groopman, J. D., Egner, P. A., Liberman, R. G., ... Tannenbaum, S. R. (2006). DNA adduct formation by 2,6-dimethyl-, 3,5-dimethyl-, and 3-ethylaniline in vivo in mice. Chemical Research in Toxicology, 19, 1086-1090. http://dx.doi.org/10.1021/tx060082q

Sun, Y. L., Zhang, Q., Schwab, J. J., Demerjian, K. L., Chen, W. N., Bae, M. S., ... Lin, Y. C. (2011). Characterization of the sources and processess of organic and inorganic aerosols in New York city with a high-resolution time-of-flight aerosol mass spectrometer. Atmospheric Chemistry and Physics, 11, 1581-1602. http://dx.doi.org/10.5194/acp-11-1581-2011

Talaska, G. (2003). Aromatic amines and human urinary bladder cancer: Exposure sources and epidemiology. Journal of Environmental Science and Health Part C-Environmental Carcinogenesis \& Ecotoxicology Reviews, 21, 29-43. http://dx.doi.org/10.1081/GNC-120021372

Talaska, G., \& Al-Zoughool, M. (2003). Aromatic amines and biomarkers of human exposure. Journal of Environmental Science and Health Part C-Environmental Carcinogenesis \& Ecotoxicology Reviews, 21, 133-164. http://dx.doi.org/10.1081/GNC-120026234

Van Hemelrijck, M. J. J., Michaud, D. S., Connolly, G. N., \& Kabir, Z. (2009). Secondhand Smoking, 4-Aminobiphenyl, and Bladder Cancer: Two Meta-analyses. Cancer Epidemiology Biomarkers \& Prevention, 18, 1312-1320. http://dx.doi.org/10.1158/1055-9965.EPI-08-0613

Ward, E. M., Sabbioni, G., DeBord, D. G., Teass, A. W., Brown, K. K., Talaska, G. G., ... Streicher, R. P. (1996). Monitoring of aromatic amine exposures in workers at a chemical plant with a known bladder cancer excess. Journal of the National Cancer Institute, 88, 1046-1052. http://dx.doi.org/10.1093/jnci/88.15.1046

Zhu, J. P., \& Aikawa, B. (2004). Determination of aniline and related mono-aromatic amines in indoor air in selected Canadian residences by a modified thermal desorption GC/MS method. Environment International, 30, 135-143. http://dx.doi.org/10.1016/S0160-4120(03)00168-5

Zhu, J. P., Newhook, R., Marro, L., \& Chan, C. C. (2005). Selected volatile organic compounds in residential air in the city of Ottawa, Canada. Environmental Science \& Technology, 39, 3964-3971. http://dx.doi.org/10.1021/es050173u 


\section{Copyrights}

Copyright for this article is retained by the author(s), with first publication rights granted to the journal.

This is an open-access article distributed under the terms and conditions of the Creative Commons Attribution license (http://creativecommons.org/licenses/by/3.0/). 